\title{
Single-Leg Roman Chair Hold Is More Effective Than the Nordic Hamstring Curl in Improving Hamstring Strength-Endurance in Gaelic Footballers With Previous Hamstring Injury
}

Citation for published version (APA):

Macdonald, B., O'Neill, J., Pollock, N., \& Van Hooren, B. (2019). Single-Leg Roman Chair Hold Is More Effective Than the Nordic Hamstring Curl in Improving Hamstring Strength-Endurance in Gaelic Footballers With Previous Hamstring Injury. Journal of Strength and Conditioning Research, 33(12), 33023308. https://doi.org/10.1519/JSC.0000000000002526

Document status and date:

Published: 01/12/2019

DOI:

10.1519/JSC.0000000000002526

Document Version:

Publisher's PDF, also known as Version of record

\section{Document license:}

Taverne

\section{Please check the document version of this publication:}

- A submitted manuscript is the version of the article upon submission and before peer-review. There can be important differences between the submitted version and the official published version of record. People interested in the research are advised to contact the author for the final version of the publication, or visit the DOI to the publisher's website.

- The final author version and the galley proof are versions of the publication after peer review.

- The final published version features the final layout of the paper including the volume, issue and page numbers.

Link to publication

\footnotetext{
General rights rights.

- You may freely distribute the URL identifying the publication in the public portal. please follow below link for the End User Agreement:

www.umlib.nl/taverne-license

Take down policy

If you believe that this document breaches copyright please contact us at:

repository@maastrichtuniversity.nl

providing details and we will investigate your claim.
}

Copyright and moral rights for the publications made accessible in the public portal are retained by the authors and/or other copyright owners and it is a condition of accessing publications that users recognise and abide by the legal requirements associated with these

- Users may download and print one copy of any publication from the public portal for the purpose of private study or research.

- You may not further distribute the material or use it for any profit-making activity or commercial gain

If the publication is distributed under the terms of Article $25 \mathrm{fa}$ of the Dutch Copyright Act, indicated by the "Taverne" license above, 


\title{
Single-Leg Roman Chair Hold Is More Effective Than the Nordic Hamstring Curl in Improving Hamstring Strength-Endurance in Gaelic Footballers With Previous Hamstring INJURY
}

\author{
Ben Macdonald, ${ }^{1}$ John O’Neill, ${ }^{\mathbf{2}}$ Noel Pollock, ${ }^{3}$ and Bas Van Hooren ${ }^{\mathbf{4}, 5}$ \\ ${ }^{1}$ British Athletics, National Performance Institute, Loughborough University, Loughborough, United Kingdom; ' ${ }^{2}$ 'Neill \\ Physiotherapy and Sports Injury Clinic, Ballyconnell, County Cavan, Ireland; ${ }^{3}$ British Athletics, High Performance Center, Lee \\ Valley, London, United Kingdom; ${ }^{4}$ Department of Human Movement Science, NUTRIM School of Nutrition and Translational \\ Research in Metabolism, Maastricht University Medical Centert, Maastricht, the Netherlands; and ${ }^{5}$ Institute of Sport Studies, \\ Fontys University of Applied Sciences, Eindhoven, the Netherlands
}

\begin{abstract}
Macdonald, B, O'Neill, J, Pollock, N, and Van Hooren, B. Single-leg Roman chair hold is more effective than the Nordic hamstring curl in improving hamstring strength-endurance in Gaelic footballers with previous hamstring injury. J Strength Cond Res 33(12): 3302-3308, 2019-Poor hamstring strength-endurance is a risk factor for hamstring injuries. This study investigated the effectiveness of the single-leg Roman hold and Nordic hamstring curl in improving hamstring strength-endurance. Twelve Gaelic footballers (mean $\pm S D$ age, height, and mass were $25.17 \pm 3.46$ years, $179.25 \pm$ $5.88 \mathrm{~cm}, 85.75 \pm 4.75 \mathrm{~kg}$, respectively) with a history of hamstring injury were randomized into 2 groups that performed 6 weeks of either Nordic hamstring curl or single-leg Roman chair hold training. The single-leg hamstring bridge (SLHB) was measured before and after intervention. The Roman chair group showed a very likely moderate magnitude improvement on SLHB performance for both legs $(23.7 \%$ for the previously injured leg [90\% confidence interval 9.6-39.6\%] and 16.9\% for the noninjured leg [6.2-28.8\%]). The Nordic curl group showed a likely trivial change in SLHB performance for the noninjured leg $(-2.1 \%$ [ -6.7 to $2.6 \%])$ and an unclear, but possibly trivial change for the previously injured leg $(0.3 \%$ [ -5.6 to $6.6 \%]$ ). The Roman chair group improved very likely more with a moderate magnitude in both the noninjured $(19.5 \%[8.0-32.2 \%])$ and the previously injured leg (23.3\%
\end{abstract}

Address correspondence to Ben Macdonald, bmacdonald@ britishathletics.org.uk.

33(12)/3302-3308

Journal of Strength and Conditioning Research

(C) 2018 National Strength and Conditioning Association
[8.5-40.0\%]) compared with the Nordic curl group. This study demonstrated that 6-week single-leg Roman chair training substantially improved SLHB performance, suggesting that it may be an efficacious strategy to mitigate hamstring (re-) injury risk. Conversely, 6-week Nordic curl training did not substantially improve SLHB performance, suggesting this may not be the intervention of choice for modifying this risk factor.

KEY WoRDS injury prevention, fatigue, hamstrings, eccentric, isometric

\section{INTRODUCTION}

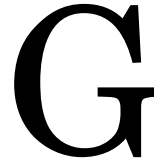
aelic football (GF) is a field sport characterized by high-speed multidirectional movements requiring high levels of endurance, agility, and strength (17). Seventy-six percent of all injuries reported in GF are to the lower limb, with hamstring injuries being the most prevalent at $24 \%$ (16). This is in keeping with other field sports where hamstring injury incidence is high and recurrence rates are common $(4,28)$. Because of the time loss incurred after a hamstring muscle injury, there is the potential for significant impact on subsequent performance, as success or failure has been linked to the number of weeks lost in a number of team and individual sports (6). Identifying athletes at risk of hamstring injury and developing effective prevention strategies to modify this risk is therefore a priority for clinicians working within GF.

Fatigue has been suggested as a risk factor for hamstring injury, with a recognized increase in football and rugby match-related injuries in the final quarter of each half $(4,28)$. For example, Woods et al. (28) reported that $47 \%$ of hamstring injuries were sustained during the final 15 minutes of the first and second halves of match play in soccer. Fatigue reduces the amount of energy that can be absorbed by

3302 Journal of Strength and Conditioning Research 
a lengthening muscle before reaching failure (13), whereas eccentric hamstring torque $(14,23)$, myoelectric activity of the biceps femoris (24), and coordination variability (20) are also impaired under fatigue. These impairments as a result of fatigue may lead to hamstring injuries. Furthermore, Schuermans et al. (22) found that the risk of reinjury in soccer players was associated with a substantial deficit in hamstring strength-endurance, as measured by a prone leg curl to exhaustion test. In agreement with this, Australian rules football players with a pre-season deficit (less than 25 repetitions) in another strength-endurance test, the singleleg hamstring bridge (SLHB), were significantly more likely to sustain a hamstring injury on the right side during the season (8). Taken together, these findings suggest that deficits in hamstring strength-endurance increase the risk of hamstring injuries. Identifying interventions that can effectively improve hamstring strength-endurance are therefore required.

Traditionally, exercises thought to produce an eccentric muscle fiber action such as the Nordic hamstring curl have been used to modify hamstring injury risk. Several studies have demonstrated increased hamstring strength and fascicle length after a training program that included the Nordic curl $(3,15)$. In addition, a recent study found that 4 weeks of Nordic curl training with emphasis on either muscular strength or endurance both reduced the loss of eccentric strength after a soccer-specific fatiguing protocol (14). Recently, isometric loading such as the single-leg Roman chair hold has been advocated as an alternative strength training intervention to prevent hamstring injuries $(26,27)$. Van Hooren and Bosch $(26,27)$ hypothesized that high-intensity isometric exercises may be more effective to condition the hamstrings for high-speed running than eccentric exercises because they more specifically replicate the isometric muscle fiber action that the hamstrings are believed to perform during the swing phase of high-speed running.

The effect of the Nordic hamstring curl and the single-leg Roman chair hold on hamstring strength-endurance has not been investigated. Therefore, the primary aim of this study is to compare the effects of a 6-week training intervention involving either the single-leg Roman chair hold or the Nordic hamstring curl on hamstring strength-endurance. A secondary aim is to investigate whether the effectiveness of these exercises in improving hamstring strength-endurance differs between the previously injured and noninjured leg.

\section{Methods}

\section{Experimental Approach to the Problem}

The dependent variable in this study was the SLHB test, which assesses hamstring strength-endurance and has demonstrated predictive value for future hamstring injury. The Nordic curl and single-leg Roman chair exercises are 2 commonly used exercises in hamstring rehabilitation, and were the independent variables in this study.

\section{Subjects}

Ethical approval was sought and received by the Bath University Research Ethics Approval Committee for Health. All players were informed of the aims and methods of the study and were given the opportunity to remove their consent and data from submission. All participants were required to complete a written consent form for their data to be collected and used during the investigation. To recruit participants, information sheets were sent to all senior GF clubs in County Cavan, Fermanagh, and Leitrim. Gaelic football consists of junior, intermediate, and senior levels from 17 years of age. Senior footballers represent the highest level of club football and are the strongest, fastest, and most skillful athletes. Inclusion criteria required participants to play GF at this senior level and have a history of hamstring injury. Exclusion criteria were a lower-limb or spinal condition requiring current medical attention. Twelve participants (mean $\pm S D$ age $25.17 \pm 3.46$ years, mass $85.75 \pm 4.75 \mathrm{~kg}$ ) from those who volunteered satisfied these criteria and attended for testing. Three subjects had a history of left hamstring injury and 9 had a history of right hamstring injury. None of the players had suffered bilateral tears. Five of the previous injuries occurred within 6 months of the start of the study. Eleven of the injuries were diagnosed clinically and ranged between a grade $1-3$ strain, whereas one injury was a tendon rupture requiring surgery. Three players were left-leg dominant for kicking, whereas 9 were right-leg dominant. Five players had suffered a hamstring injury in their kicking or dominant leg and 7 players in their nondominant leg.

\section{Procedures}

The 12 participants were randomly divided into 2 groups. Group $1(n=6$, mean $\pm S D$ age $25.7 \pm 1.75$ years, height $177.5 \pm 5.96 \mathrm{~cm}$, mass $85.7 \pm 4.46 \mathrm{~kg}$ ) completed 6-week single-leg Roman chair hold training and Group $2(n=6$, mean $\pm S D$ age $24.7 \pm 4.76$ years, height $181.0 \pm 5.76 \mathrm{~cm}$, mass $85.8 \pm 5.46 \mathrm{~kg}$ ) completed 6-week Nordic hamstring curl training. Preintervention and postintervention assessment of the SLHB took place at Kildallan Gaelic Athletic Football club. This took place across 3 evenings due to the work commitments of the participants, at the end of the GF season in December 2015. The 6-week training intervention finished in January 2016. Participants were given a testing and exercise familiarization session before baseline testing and the intervention period commencing. Exercises were demonstrated by a physiotherapist experienced in hamstring injury management in Gaelic footballers. All players were given a weekly phone call by the physiotherapist to encourage compliance and assess progress. The training intervention was completed at the individual participant's club.

The Nordic curl is thought to produce an eccentric hamstring muscle fiber action and was progressed as per a previously described protocol (Table 1) (18). The participant is positioned in a kneeling position with knees placed at 
TABLE 1. Roman chair hold and Nordic curl training programs.

\begin{tabular}{|c|c|c|c|c|}
\hline \multirow[b]{2}{*}{ Week } & \multirow[b]{2}{*}{$\begin{array}{l}\text { Session/ } \\
\text { week }\end{array}$} & Reps/sets & \multirow{2}{*}{$\begin{array}{c}\begin{array}{c}\text { Reps/ } \\
\text { sets }\end{array} \\
\begin{array}{c}\text { Nordic } \\
\text { curl }\end{array}\end{array}$} & \multirow[b]{2}{*}{$\begin{array}{l}\text { Time under tension (s) for Roman chair vs. Nordic curl } \\
\text { groups }{ }^{\star}\end{array}$} \\
\hline & & Single-leg Roman chair hold & & \\
\hline 1 & 1 & 10-s hold $\times 3$ & $5 \times 2$ & 30 vs. 26 \\
\hline 2 & 2 & $\begin{array}{c}10 \text {-s holds } \times 3 \text { with } 10 \mathrm{~kg} \\
\text { mass }\end{array}$ & $6 \times 2$ & 30 vs. 31 \\
\hline 3 & 3 & $\begin{array}{c}10 \text { plate rows with } 10 \mathrm{~kg} \text { mass } \\
\times 3\end{array}$ & $6 \times 3$ & 30 vs. 47 \\
\hline 4 & 3 & As previous week & $8 \times 3$ & 30 vs. 62 \\
\hline 5 & 3 & 10 rows with $20 \mathrm{~kg}$ mass $\times 3$ & $10 \times 3$ & 30 vs. 78 \\
\hline 6 & 3 & As previous week & $10 \times 3$ & 30 vs. 78 \\
\hline
\end{tabular}

${ }^{*}$ Time under tension was calculated as the number of reps multiplied by the number of sets and the duration of a repetition. For the Roman chair group, all repetitions had a duration of approximately 10 seconds. For the Nordic curl group, all repetitions were estimated to have a duration of approximately 2.6 seconds based on previous research (5).

$90^{\circ}$ and hips and spine in neutral extension. The participant is then held by the ankles by a training partner and is encouraged to lower their body as slowly as possible toward the floor aiming to ensure that hips and lumbar spine maintain the neutral position. Hands and arms are used to catch the fall, before returning to the start position by walking back up using the hands (Figure 1).

The single-leg Roman chair hold is thought to produce a predominantly isometric muscle fiber action and was performed in a glute-hamstring machine, as described previously (27). As well as a practical familiarization session, a video of the technique was used to ensure clarity of tech-

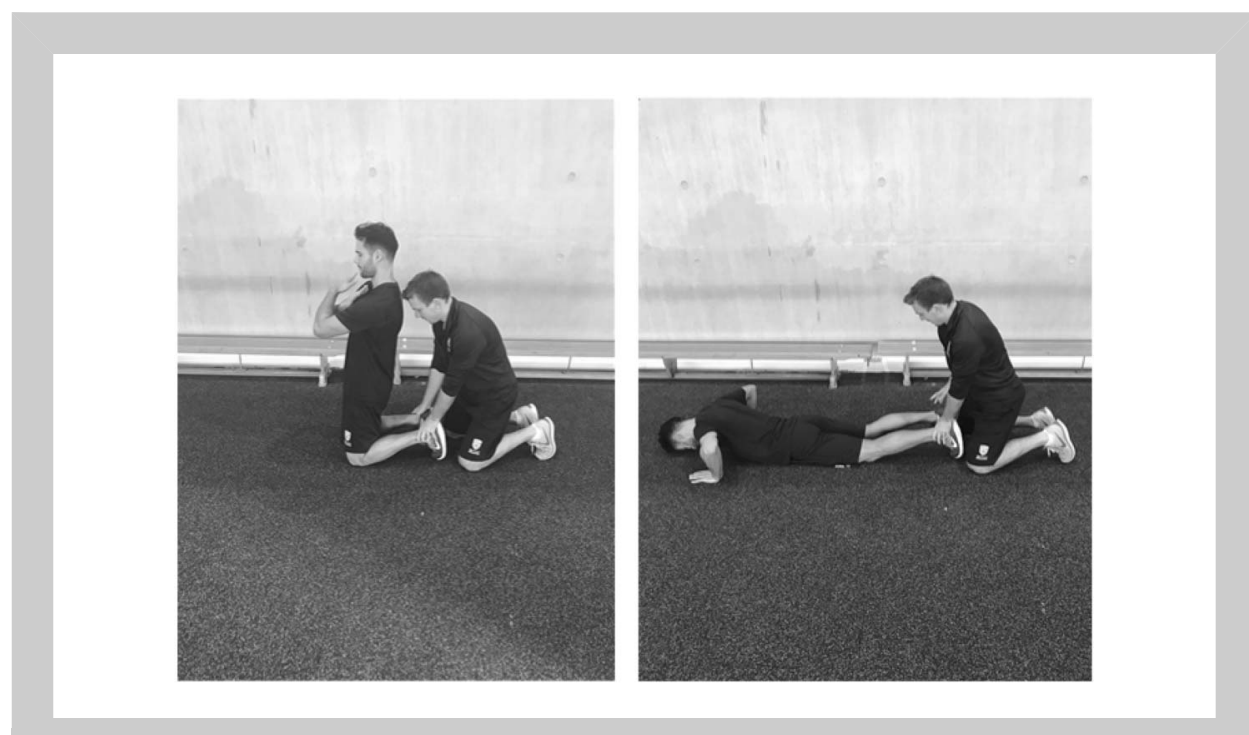

Figure 1. Nordic hamstring curl start (left) and finish (right) positions. nique. Participants were positioned prone in the machine with knees in slight extension and ankles hooked under a pad. They were then asked to raise their trunk upward into hip-lumbar neutral, before taking their weight onto one leg with the contralateral leg above the pad to ensure that a single-leg condition was achieved (Figure 2). This was then held isometrically for 10 seconds and progressed as per the training protocol described in Table 1.

The primary outcome measure was the number of repetitions during the SLHB. Freckleton et al. (8) described this test as being reliable with intratester intraclass correlation coefficient and intertester intraclass correlation coefficient ranging from 0.77 to 0.89 and 0.89 to 0.91 , respectively. Participants were instructed as per a previously described protocol (8). In a supine position with one heel on a $60-\mathrm{cm}$ box, the test leg was placed at $20^{\circ}$ knee flexion using a goniometer (Figure 3). All participants were requested to place their arms across their chest and push through their heel to lift their hips off the ground, and lower down again. This was performed using a 1-2-3 count, up and down, and was strictly enforced by the physiotherapist present. Full hip extension to $0^{\circ}$, and full return to the floor was required for each repetition or the test was 

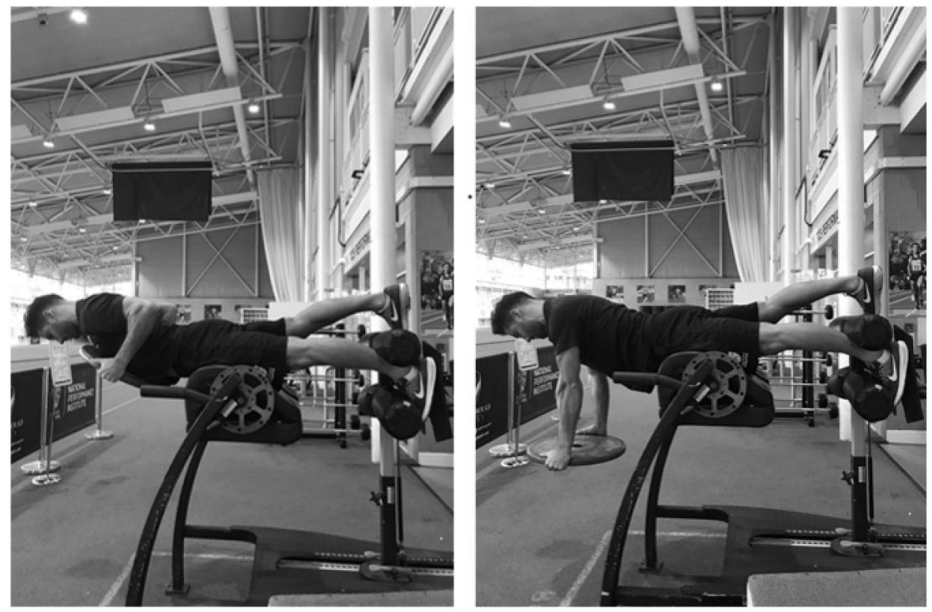

Figure 2. Single-leg Roman chair hold start (left) and finish (right) positions.

discontinued. The physiotherapist visually assessed this. The participants were instructed to complete as many repetitions as possible to failure. The test was performed with only the assessing physiotherapist present and constant feedback and encouragement were given to ensure best technique. When the participant lost the correct technique in terms of range of movement described, or could not maintain proper pacing, they were given a warning, with the test halted at the next lapse. The left leg was always assessed before the right leg.

\section{Statistical Analyses}

Statistical spreadsheets were used to log-transform all data to reduce bias arising from nonuniformity error. Data from the previously injured and noninjured leg were then analyzed separately for practical significance using nonclinical magnitude-based inference (2,11). A spreadsheet for the analysis of parallel-group controlled trials with pretest values as covariate was used to determine between-group differences after training (10). Within-group changes from pretrain-

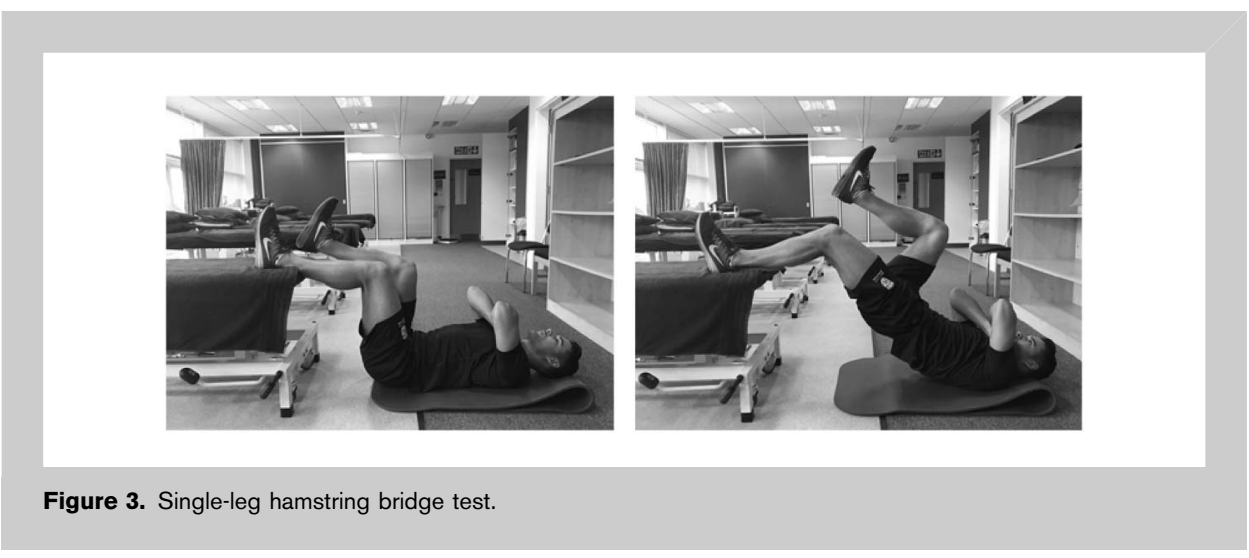

\section{Results}

\section{Within-Group Comparison}

ing to posttraining were determined using a spreadsheet for analyzing a post-only crossover. For the between-group and within-group comparison, the chances that the (true) difference in performance was better (beneficial), similar (trivial), or worse (harmful) than the smallest worthwhile change $(0.2$ multiplied by the between-subject $S D$, based on Cohen's $d$ principle) was calculated. Quantitative changes of beneficial, similar, or worse performance were assessed and reported qualitatively using the following scale: 25-75\%, possibly; 75-95\%, likely; 95-99.5\%, very likely; and $>99.5 \%$, most likely, almost certainly. If the chance of benefit and harm was $>5 \%$, the true differences were considered unclear. In this case, the largest chance for a change was reported to give an indication of the most likely change (11). To determine the magnitude of the change, standardized differences were calculated as the difference between the log-transformed mean values divided by the pooled pretest $S D$ for the analyzed leg. Standardized differences were qualitatively reported as $<0.2$, trivial; 0.2-0.6, small; 0.6-1.2, moderate; $1.2-2.0$ large; and $>2.0$, very large. Mean $\pm S D$, the back-transformed percentage change from pretest (within-group analysis) or percentage difference (between-group analysis), and the 90\% confidence intervals (CIs; which define the likely range of the true value for a larger population) were also reported.

The results of the within-group analysis are reported in Table 2. The single-leg Roman chair hold group showed a very likely moderate magnitude improvement on SLHB performance for both legs. By contrast, the Nordic curl group showed a likely trivial change in SLHB performance for the noninjured leg and an unclear, but possible ( $80 \%$ chance) trivial change for the previously injured leg.

\section{Between-Group Comparison}

Before training, the Roman chair group had possibly a better SLHB performance with 
TABLE 2. Changes in the number of repetitions on the SLHB from pretraining to posttraining.*

\begin{tabular}{|c|c|c|c|c|}
\hline Group & Pre $($ mean $\pm S D)$ & Post (mean $\pm S D$ ) & $\%$ Difference $(90 \% \mathrm{Cl})$ & Qualitative assessment \\
\hline \multicolumn{5}{|l|}{$\begin{array}{l}\text { Single-leg Roman } \\
\text { chair group }\end{array}$} \\
\hline $\begin{array}{l}\text { Previously injured } \\
\text { leg }\end{array}$ & $32.2 \pm 6.9$ & $39.7 \pm 7.5$ & 23.7 (9.6 to 39.6$)$ & $\begin{array}{c}\text { Very likely moderate } \\
\text { improvement }\end{array}$ \\
\hline Noninjured leg & $35.0 \pm 6.1$ & $40.8 \pm 6.7$ & $16.9(6.2$ to 28.8$)$ & $\begin{array}{l}\text { Very likely moderate } \\
\text { improvement }\end{array}$ \\
\hline \multicolumn{5}{|l|}{ Nordic curl group } \\
\hline $\begin{array}{l}\text { Previously injured } \\
\text { leg }\end{array}$ & $35.8 \pm 6.9$ & $36.2 \pm 8.2$ & $0.3(-5.6$ to 6.6$)$ & $\begin{array}{c}\text { Unclear, } 80 \% \text { chance for } \\
\text { a trivial change }\end{array}$ \\
\hline Noninjured leg & $32.3 \pm 6.7$ & $31.7 \pm 6.7$ & $-2.1(-6.7$ to 2.6$)$ & Likely trivial \\
\hline
\end{tabular}

${ }^{*} \mathrm{SLHB}=$ single-leg hamstring bridge; $\mathrm{Cl}=$ confidence interval.

a small magnitude $(9.0 \%$ [90\% CI -12.0 to $34.9 \%])$ for the previously noninjured leg compared with the Nordic curl group. For the previously injured leg, the Roman chair group had possibly a worse SLHB performance with a small $(-10.6 \%$ [ -27.4 to $10.2 \%]$ ) magnitude compared with the Nordic group. The single-leg Roman chair group improved very likely more with a moderate magnitude in both the noninjured leg $(19.5 \%$ [90\% CI 8.0-32.2]) and the previously injured leg (23.3\% [8.540.0]) compared with the Nordic curl group. The raw data can be found online (http://links.lww.com/JSCR/A88).

\section{Discussion}

The primary objective of this study was to determine the effectiveness of the Nordic curl and single-leg Roman chair hamstring exercise programs in improving hamstring strength-endurance as measured during the SLHB. Our findings demonstrate that a 6-week single-leg Roman chair program resulted in substantially greater improvements in the SLHB test than a 6 -week Nordic curl program in a sample of Gaelic footballers. Improvements in SLHB scores in the single-leg Roman chair group occurred with a similar magnitude in both the previously injured and uninjured limbs.

Fatigue is consistently associated with hamstring injury in injury surveillance studies $(4,28)$, and has been reported to negatively affect hamstring strength, function, and mechanics $(14,22,23)$. Freckleton et al. (8) showed that players with a pre-season deficit (less than 25 repetitions) in the SLHB were significantly more likely to sustain a hamstring injury on the right side during the season. It has recently been argued that the muscle fibers of the hamstrings remain predominantly isometric during the swing phase of high-speed running, despite an overall increase in muscle-tendon unit length. A fatigue-induced reduction in force output from the muscle fibers would result in an inability of the muscle fibers to remain isometric, with a resultant increase in length and microdamage occurring (26). This mechanism may explain the association described between fatigue and injury. The results of the current study suggest that isometric strength training may positively impact on injury risk by improving hamstring strength-endurance, and modifying this potential injury process.

Although suggested protocols for Nordic hamstring curl training include multiple repetitions, it is usual for there to be a brief rest period between repetitions as the athlete returns to the starting position (5). In addition, a Nordic curl repetition has been shown to last less than 3 seconds, with surface electromyography levels of the hamstrings reducing as the knee approaches terminal extension (5). Therefore, a prolonged activation pattern is not achieved compared with the Roman chair holds used in this study, where the training protocol commenced with a 10 -second continuous contraction. It has previously been demonstrated that voluntary activation of the quadriceps is higher during sustained isometric contractions than during eccentric or concentric actions (1). Although it is unknown whether higher muscle activity also leads to better training adaptations, Kay et al. (12) found a greater fatiguing stimulus during isometric contractions compared with eccentric or concentric muscle actions. They suggested that ischemia due to elevated intramuscular pressure that compresses blood vessels, or an increase in metabolic by-products, as a possible cause of this. This may possibly explain the greater improvements in SLHB demonstrated by the Roman chair group in this study. Specificity is one of the key principles of any training intervention. Therefore, if the aim is to provide an endurance-based training stimulus to build fatigue resistance, it seems logical that the longer-duration contraction of the single-leg Roman chair hold is more likely to achieve this.

Although the Nordic curl exercise has been demonstrated to reduce hamstring injury risk $(18,25)$ and should therefore be included in a preventative program for hamstring injuries, 
this study suggests that an isometric exercise such as the single-leg Roman chair hold is also important to improve hamstring strength-endurance and mitigate muscle fatigue as a risk factor for injury. In addition, being able to perform more than 30 repetitions on the SLHB has been suggested as a progression criterion for sport-specific movement testing in a return to sport algorithm after hamstring injuries (7). Including the single-leg Roman chair hold during rehabilitation may therefore lead to a faster return to sport, although this should not be at the expense of more reinjures. Both the noninjured and previously injured leg showed substantial improvements in SLHB performance for the isometric group. Therefore, this exercise could be used to both prevent hamstring injuries and during rehabilitation after an injury, by improving hamstring strength-endurance. It is important to note that the holding isometric exercise used in this study may have different effects compared with a pushing isometric exercise (21) such as the single-leg supine bridge. Therefore, these findings cannot directly be generalized to other (pushing) isometric exercises.

When interpreting the current findings, a number of limitations should be considered. Although weekly phone calls were made to encourage compliance, this was not officially measured. The sample size of the study was also low, which particularly affected the ability to draw any conclusions regarding the impact of previous injury. Specifically, although the qualitative statistical inference based on the effect size was a "moderate" magnitude for both the previously injured and noninjured leg in the Roman chair group, the previously injured leg showed an almost 24\% improvement compared with an almost $17 \%$ improvement in the noninjured leg (Table 2). This suggests that the previously injured leg could benefit more from this intervention, but more research is required to substantiate this notion. The order of limb testing was not randomized and this could potentially lead to contralateral fatigue, which may have influenced our findings (9). Future studies should therefore randomize the order of limb testing. The sample was taken from senior GF teams and, as such, these results may not be applicable to other sports. Although all participants had a history of hamstring muscle injury, there have been recent advances in muscle injury classification (19) and randomization did not control for specific diagnoses. As a result, more individuals in the Roman chair group recently sustained an injury (5 in 2015) compared with the Nordic curl group (3 in 2015). Therefore, one could argue that the individuals in the Roman chair group were more deconditioned due to the recent injuries and hence had a greater potential to improve during the intervention. Indeed, in the pretest, there was a possible small difference in the number of reps that could be completed on the SLHB between the groups (Table 2), with the Roman chair group performing less repetitions for the previously injured leg. However, the individuals in the Roman chair group could complete more repetitions with the non- injured leg on the SLHB during the pretest, making it unlikely that the individuals in the Roman chair group were overall more deconditioned and showed larger improvements solely due to the more recent injury. Finally, it is also possible that the training stimulus in the Nordic group was not high enough to cause any training adaptation. However, this study used a previously established training protocol that has been shown to be effective in reducing hamstring injury rates in soccer players (18). In addition, the Nordic curl is a supramaximal exercise and none of the players in this study could reach full knee extension during the Nordic curl without dropping down, suggesting that the intensity of the exercise was high enough. Furthermore, the time under tension (Table 1) was estimated using previous research on the Nordic curl (5), and was also higher for the Nordic curl group with total time under tension being approximately 2 times higher for the Nordic curl group compared with the Roman chair group (322 vs. 180 seconds, respectively). Therefore, it is unlikely that the training stimulus for the Nordic group was too low. Future studies should compare the effects of an "endurance" based Nordic curl program (14) to an "endurance" based single-leg Roman chair hold program such as used in this study.

\section{Practical Applications}

Hamstring injuries are common during sports requiring high-speed running, and prevention strategies to date have largely failed to improve injury rates. The SLHB test assesses hamstring strength-endurance and poor performance on this test has demonstrated predictive value for future hamstring muscle injury. Although the Nordic hamstring curl is widely used to condition the hamstrings to prevent muscle injury, it has recently been hypothesized that the single-leg Roman chair hold is also an effective exercise to prevent hamstring injuries. This study demonstrated that GF players who completed a 6-week program of isometric hamstring strengthening had a substantial improvement in SLHB performance on both the previously injured and noninjured leg, whereas players performing 6week eccentric training did not demonstrate substantial improvements in either of the legs. Coaches and athletes should therefore consider using isometric hamstring exercises, such as the single-leg Roman chair hold, as an intervention for both injury prevention and rehabilitation in hamstring muscle injury.

\section{ACKNowledgments}

The authors thank the participants from the County Cavan, Fermanagh, and Leitrim Gaelic football clubs for their time given up to complete testing sessions. The authors also thank Will Hopkins for his assistance with the statistical analysis. No financial assistance was gained for this project and the authors disclose no conflict of interest. 


\section{REFERENCES}

1. Babault, N, Pousson, M, Ballay, Y, and Van Hoecke, J. Activation of human quadriceps femoris during isometric, concentric, and eccentric contractions. J Appl Physiol (1985) 91: 2628-2634, 2001.

2. Batterham, AM and Hopkins, WG. Making meaningful inferences about magnitudes. Int J Sports Physiol Perform 1: 50-57, 2006.

3. Bourne, MN, Duhig, SJ, Timmins, RG, Williams, MD, Opar, DA, Al Najjar, A, Kerr, GK, and Shield, AJ. Impact of the Nordic hamstring and hip extension exercises on hamstring architecture and morphology: Implications for injury prevention. Br J Sports Med 51: 469-477, 2017.

4. Brooks, JHM, Fuller, CW, Kemp, SPT, and Reddin, DB. Incidence, risk, and prevention of hamstring muscle injuries in professional rugby union. Am J Sports Med 34: 1297-1306, 2006.

5. Ditroilo, M, De Vito, G, and Delahunt, E. Kinematic and electromyographic analysis of the Nordic hamstring exercise. $J$ Electromyogr Kinesiol 23: 1111-1118, 2013.

6. Drew, MK, Raysmith, BP, and Charlton, PC. Injuries impair the chance of successful performance by sportspeople: A systematic review. Br J Sports Med 51: 1209-1214, 2017.

7. Erickson, LN and Sherry, MA. Rehabilitation and return to sport after hamstring strain injury. J Sport Health Sci 6: 262-270, 2017.

8. Freckleton, G, Cook, J, and Pizzari, T. The predictive validity of a single leg bridge test for hamstring injuries in Australian Rules Football Players. Br J Sports Med 48: 713-717, 2014.

9. Halperin, I, Chapman, DW, and Behm, DG. Non-local muscle fatigue: Effects and possible mechanisms. Eur J Appl Physiol 115: 2031-2048, 2015.

10. Hopkins, WG. Spreadsheets for analysis of controlled trials, crossovers and time series. Sportscience 21: 1-4, 2017.

11. Hopkins, WG, Marshall, SW, Batterham, AM, and Hanin, J. Progressive statistics for studies in sports medicine and exercise science. Med Sci Sports Exerc 41: 3-13, 2009.

12. Kay, D, St Clair Gibson, A, Mitchell, MJ, Lambert, MI, and Noakes, TD. Different neuromuscular recruitment patterns during eccentric, concentric and isometric contractions. J Electromyogr Kinesiol 10: 425-431, 2000.

13. Mair, SD, Seaber, AV, Glisson, RR, and Garrett, WE Jr. The role of fatigue in susceptibility to acute muscle strain injury. Am J Sports Med 24: 137-143, 1996.

14. Matthews, MJ, Heron, K, Todd, S, Tomlinson, A, Jones, P, Delextrat, $A$, and Cohen, DD. Strength and endurance training reduces the loss of eccentric hamstring torque observed after soccer specific fatigue. Phys Ther Sport 25: 39-46, 2017.

15. Mjolsnes, R, Arnason, A, Osthagen, T, Raastad, T, and Bahr, R. A 10 -week randomized trial comparing eccentric vs. concentric hamstring strength training in well-trained soccer players. Scand J Med Sci Sports 14: 311-317, 2004.

16. Murphy, JC, O’Malley, E, Gissane, C, and Blake, C. Incidence of injury in Gaelic football: A 4-year prospective study. Am J Sports Med 40: 2113-2120, 2012.

17. O’Malley, E, Murphy, J, Gissane, C, and Blake, C. Epidemiology of lower limb injury in Gaelic football and hurling. Br J Sports Med 48: 646-647, 2014.

18. Petersen, J, Thorborg, K, Nielsen, MB, Budtz-Jørgensen, E, and Hölmich, P. Preventive effect of eccentric training on acute hamstring injuries in men's soccer: A cluster-randomized controlled trial. Am J Sports Med 39: 2296-2303, 2011.

19. Pollock, N, James, SL, Lee, JC, and Chakraverty, R. British athletics muscle injury classification: A new grading system. Br J Sports Med 48: 1347-1351, 2014.

20. Samaan, MA, Hoch, MC, Ringleb, SI, Bawab, S, and Weinhandl, JT. Isolated hamstrings fatigue alters hip and knee joint coordination during a cutting maneuver. J Appl Biomech 31: 102-110, 2015.

21. Schaefer, LV and Bittmann, FN. Are there two forms of isometric muscle action? Results of the experimental study support a distinction between a holding and a pushing isometric muscle function. BMC Sports Sci, Med Rehabil 9: 11, 2017.

22. Schuermans, J, Van Tiggelen, D, Danneels, L, and Witvrouw, E. Susceptibility to hamstring injuries in soccer: A prospective study using muscle functional magnetic resonance imaging. Am J Sports Med 44: 1276-1285, 2016.

23. Small, K, McNaughton, L, Greig, M, and Lovell, R. The effects of multidirectional soccer-specific fatigue on markers of hamstring injury risk. J Sci Med Sport 13: 120-125, 2010.

24. Timmins, RG, Opar, DA, Williams, MD, Schache, AG, Dear, NM, and Shield, AJ. Reduced biceps femoris myoelectrical activity influences eccentric knee flexor weakness after repeat sprint running. Scand J Med Sci Sports 24: e299-305, 2014.

25. van der Horst, N, Smits, DW, Petersen, J, Goedhart, EA, and Backx, FJ. The preventive effect of the nordic hamstring exercise on hamstring injuries in amateur soccer players: A randomized controlled trial. Am J Sports Med 43: 1316-1323, 2015.

26. Van Hooren, B and Bosch, F. Is there really an eccentric action of the hamstrings during the swing phase of high-speed running? Part I: A critical review of the literature. J Sports Sci 35: 2313-2321, 2017.

27. Van Hooren, B and Bosch, F. Is there really an eccentric action of the hamstrings during the swing phase of high-speed running? Part II: Implications for exercise. J Sports Sci 35: 2322-2333, 2017.

28. Woods, C, Hawkins, RD, Maltby, S, Hulse, M, Thomas, A, and Hodson, A. The football association medical research programme: An audit of injuries in professional football-analysis of hamstring injuries. Br J Sports Med 38: 36-41, 2004. 